Sth International Conference on the Physics of Highly-Charged lons Giessen, September 10-14, 1990

\title{
The Status of the Electron Beam Ion Sources
}

Martin P. Stockli, J.R. Macdonald Laboratory

Kansas Statc University, Manhattan, KS $(x, 50)(20-2(x)+4$ USA

\begin{abstract}
More than twenty years after its invention, 13 Electron Beam Ion Sourees are in operation worldwide. The substantial progress in operation and insight, achicved over the last few years, made the EBISes become reliable tools for the production of beams of very highly charged, low energy ions. For example, 8 EBISes produce bare argon on a standard basis. The successful production of hydrogen-like xenon presents the ions with the highest ionization energy, whereas the production of ThSO+ presents the highest achicved charge: state. Several synchrotrons are fed by EBIS-injectors, taking advantage of the EBIS batch mode production, which yields the highest charge states. A few EBISes are used for ion source development. However, most of the EBISes' efforts are directed to rescarch the physics of highly charged ions. Some of those are used to study the electron-ion interaction inside the source. But normally, most EBISes deliver the ions for external experiments, which so far concentrate on the recombination of the highly charged ions with atoms, molecules and surfaces. The ions are typically produced at a potential of 1 to a few kilovolts per charge, but in most cases, the EBIS is mounted on a high voltage platform or is followed by an RFQ, and therefore can generate ion energies from a few hundred volts up to a few hundred kilovolts per charge. The delivered beams have a low emittance and a low cnergy spread, which is an advantage for high resolution experiments. This paper presents briefly all operational EBISes, their capabilities, their achicvements, and their contribution to physics research.
\end{abstract}

\section{Introduction}

More than twenty years ago Donets proposed the concept for an Elcctron Beam Ion Source (EBIS) to produce highly charged ions $\{1\}$. Briefly, ions trapped inside an electron beam are stripped electron by electron. As shown in Figure 1, a strong magnetic solenoid is commonly used to confine and compress the electron beam, which

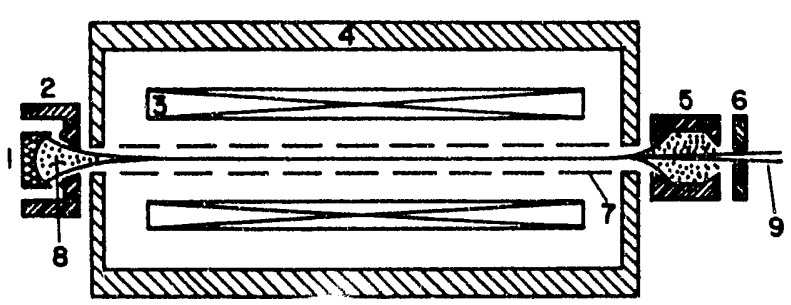

Fig. 1. Schematic of an $t_{1}$ aron Beam Ion Source with the cathode (1) and the anode (2) of its electron gun, the solenoid (3) with its magnetic shield (4). the collector (5) with its repeller (6) and the drift

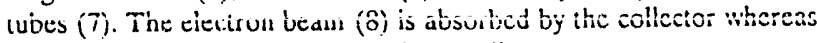
the ion beam (9) is extracted by the repeller. increases the ionization rate. The highest charge states are obtained with the long confinement times achieved with a batch mode. In this mode, the electrostatic potential of the drift tubes is altered in a time sequence, first to provide for the injection of low charged ions, then to form a trap in which the ions are cooked and finally to expel the ions when the desired charge state is reached. However, the capture of electrons from the residual gas often limits the ultimate obtainable charge state, a limitation which is extended by the low residual pressures achieved in CRYogenic EBISes (CRYEBIS). Although the basic opcration schema appears simple, there are complex interactions involved. In particular, the last "International Symposium on Electron Beam lon Sources and their Applications" held at Brookhaven National Laboratory in November 1988 revealed at substantial progress in the operational performance and understanding of the characteristics of the various EBISes, such as the recognition and intentional application of ion-ion cooling which counteracts the electron beam induced ion heating, pioneered by the Livermore group [2,3] and Doncts [4]. In addition to the symposium's proceedings [5], there are many other publications [6-8] which discuss the physics and technology of such sources, as well as the operation, performance, and achievements of the individual EBISes. In summary, there are quite a few fully operatienal EBISes, which are producing highly and very highly charged ions for physics research, or in some cases are used to study physics inside the source. Beams of bare argon became an operational standard and naturally beams of heavier, much higher charged ions can be casily produced. However, the construction and operation of an EBIS remains a challenging task and over the years several EBIS programs were shut down before their device was fully operational. Despitc their misfortune, those groups have contributed substantially to the knowledge of our field and therefore helped some of us to succeed. But we do not have time to discuss the history of the development, as we want to concentrate on today's status of the operational EBISes, their contribution to physics research, and the new opportunities for the highly charged ion physicists.

\section{The Russian Challenge}

The Synchrophasotron at the Joint Institute of Nuclear Research required a charge-to-mass ratio of at least 0.5 becausc of its insufficicnt vacuum and the acceptance of its injector LINAC and therefore required the injection of fully stripped ions for heavy ion operations. Starting in 1977 this challenge was met by KRION which served as an injector until 1984, when it was replaced with a higher yielding laser source [9]. KRION was upgraded to KRION-C and now serves as a test EBIS to study a varicty of problems associated with the production of ultra-high charge states [10]. KRION-3 took on the challenge for high yields of very highly charged ions to replace or complement the present injector ion source [6]. At times KRION-3 excecds 1000 amps/sqcm current density [11] and produces more than 20 million bare argon ions in 0.2 seconds [12], but futher development is required. 


\section{DISCLAIMER}

This report was prepared as an account of work sponsored by an agency of the United States Government. Neither the United States Government nor any agency thereof, nor any of their employees, makes any warranty, express or implied, or assumes any legal liability or responsibility for the accuracy, completeness, or usefulness of any information, apparatus, product, or process disclosed, or represents that its use would not infringe privately owned rights. Reference herein to any specific commercial product, process, or service by trade name, trademark, manufacturer, or otherwise does not necessarily constitute or imply its endorsement, recommendation, or favoring by the United States Government or any agency thereof. The views and opinions of authors expressed herein do not necessarily state or reflect those of the United States Government or any agency thereof. 
However, it is KRION-2 which kecps producing the record high charge states of low energy ions such as bare Ar in 1977 [13] and bare $\mathrm{Kr}_{r}$ in 1986. Convincing proof for the production of bare krypton was delivered with the observation of the $\mathrm{Kr} \mathrm{K}$-alpha hypersatellite with increasing confinement time, when the exaracted ions impacted a copper surface $[9,14]$. A ten- to twenty-lidid increase of the yields of bare $\mathrm{Ar}$ and $\mathrm{Kr}$ ions was observed [12] when ion-ion cooling wals applied [15]. Recently the production of hydrogen-like and bare xenon was announced $[6,15]$. These statements were backed at the 1989 Ion Source conference with the proof for the emission of the $\mathrm{K}-X$-rays when the extracted xenon ions impacted on a surface [12]. Although that proof indicated only the production of hydrogen-like ions, the production of at least some fully ionized xenon is likely. This outstanding resull was achicved with a $52 \mathrm{kV}$ electron beam whizh bombarded the ions for 40 seconds [12]. Besides breaking the charge states' records, Krion-2 also provided over the years many novel dital on atomic physics, such as ionization cross sections by electron impact for highly charged ions $[12,16,17\}$ and recombination of highly charged ions with gascous targets $[11,17]$ or with surfaces $[6,9,11,14,15,17-10]$.

An EBIS with room temperature drift tubes serves as an injector to the synchrotron of the Institute of Nuclear Physics in Novosibirsk. The $50 \mathrm{~Hz}$ repetition rate limits the range for which bare nuclei can be produced.

\section{The West-European Electron Bcam Ion Sources}

The injector LINAC of the 3 GCV synchrotron SATURNE at the Centre d'Etude Nucleaire in Saclay required a charge-lo-mass ratio of 0.45 . Heavy ion operations were initiated with an injector consisting of a CRYogenic EBIS (CRYEBIS-I) followed by an RFO [20]. MIMAS, a low encrgy accumulator ring was added in 1988 to increase the yields. In 1987, after four years of successful operation, CR Y'EBIS-1 was replaced with DIONE, a second generation EBIS. The reduced residual gas pressure, the higher electron beam energy and the tenfold increase in electron beam density yielded a dramatic improvement. Up to one trillion highly charged ions such as bare carbon, nitrogen or neon, can be extracied after very short confinement times [21]. For example MIMAS can be stacked with up to 7 pulses of bare nitrogen within a quarter of a second [22]. DIONE can casily produce bare argon, but for injection it is preferable to use the higher yields of $\mathrm{Ar}^{1 \mathrm{n}}$. which can be produced in less than 50 milliseconds and slacked in
MINAS [21]. Another breakthrough was achicved with the injection of $\mathrm{Kr}^{20+}$ which SATURNE accelerated up $1059 \mathrm{GeV}$ to study high energy peripheral collisions [22,23]. Only recently was DIONE. involved in its first atomic physics experiment, which investigated th: angular momentum state of the electrons captured from the residual gas by the hydrogenlike argon ions at $7.5 \mathrm{MeV}$ [24]. And very recently a newly installed atomic hydrogen target was used to refine this experiment [25].

The French CRYEBIS program in Orsay was terminated when CRYEBIS-II did not deliver the expected results, but interestingly enough a sister of CRYEBIS-II is working successfully in Stockholm: CRYSIS, the CRYogenic Stockholm Ion Source, the only EBIS which is operated with a closed cycle refrigerat or to kecp the superconducting solenoid and the drift tubes at cryogenic temperatures. It was outlayed as the primary injector for CRYRING, a synchretron storage sing for very highly charged, heavy ions with an energy range of 0.3 to 24 MeV/amu [26]. So far CRYSIS produces with each cycle up to 100 million highly charged ions, such as bare $\mathrm{Ne}, \mathrm{Ar}^{10 \%}$ or $\mathrm{Xe}^{35}$, and less of the higher charge states such as bare argon and neon-like xenon, which require longer confinement times [27]. The highly charged xenon ions were used to study charge changing processes in collisions with helium [2S] and xenon. For the highest charge states, the latter experiment revealed evicence for radiative stabilization of the two electron transfer processes [29-31]. Recently CRYSIS, mounted on its $50 \mathrm{l} \mathrm{V}$ platform, was moved to its final location where it can serve as an injector to CRYRING. An external ion injector was added in the new setup for the production of non gascous ions. This final arrangement is very versatile, because either CRYSIS boosted by an RFQ feeds CRIRING (o) study highly charged ions at intermediate energies or CRYSIS can feed one of four low energy atomic physics beam lines with up $1050 \mathrm{kV} / \mathrm{q}$ of highly charged ions. This new facility, which welcomes guest researchers, provides a new opportunity for physicists interested in highly charged physics.

The Frankfurt EBIS is a small compact EBIS made with a $\mathrm{m}$ long, $5 \mathrm{~cm}$ bore, 5 Tesla superconducting solenoid. It reaches high electron beam densitics, and normally if is operated in a DC-mode. The production of $\mathrm{Ne}^{10+}, \mathrm{Ar}^{16+}, \mathrm{Kr}^{2 \mathrm{Kn}}$ and $\mathrm{Xe}^{36+}$ are impressive results considering the short confinement times obtained in a DC mode [32] The DC mode is preferred because of its ad.. Itages for atomic physics experiments, for which novel, high resolution instruments were developed. However, as a team of the Institute for Applied Physics, their contributions concentrate on the invention of new EBBS

Table 1: Operational EBIS-Devices 1990:

\begin{tabular}{|c|c|c|c|c|c|}
\hline LOCATION/LAB & KEY PERSONNEL & DEVICE & TRAP & PRODUCED IONS & REMARKS \\
\hline \multirow[t]{3}{*}{ Dubna/JINR } & Pikin/Donets & KRION-2 & $\mathrm{LHe}$ & $\mathrm{Ar}^{18+}, \mathrm{Ks}^{36+}, \mathrm{Xe}^{53+}$ & atomic physics \\
\hline & Vadeev/Donets & KRION-3 & $\mathrm{LHe}$ & $\mathrm{Ar}^{18}$ & future injector \\
\hline & Ovsyannikov/Donets & KRION-C & LHe & $\mathrm{Ar}^{18+}, \mathrm{U}^{50+}$ & test E:BIS \\
\hline Novosibirsk/INP & Abdul'manov & Novo.EBIS & warm & & injector \\
\hline Saclay/CEN & Faurc & DIONE & iHe & $\mathrm{Ar}^{18+}, \mathrm{Kr}^{30+}$ & injector \\
\hline Stockholm/MSI & Liljeby & CRYSIS & LHe-R & $\mathrm{Ar}^{18+}, \mathrm{Xe}^{\mathrm{Ht}}$ & 4 atornic beam lines \\
\hline Frankfurt/LAP & Kleinod/Becker & Frank.EBIS & $\mathrm{LHe}$ & $\mathrm{Ar}^{10+}, \mathrm{Kr}^{20+}, \mathrm{Xe}^{36+}$ & DC-operation \\
\hline Nagoya/IPP & Tawara & NICE & $\mathrm{LHe}$ & $\mathrm{Ne}^{\mathrm{i0}+}, \mathrm{Kr}^{25+}, \mathrm{I}^{\mathrm{d2}+}$ & DC-operation \\
\hline Tokyo/Metro U. & Okuno & Mini-EBIS & LN2 & $\mathrm{C}^{\mathrm{s} *}, \mathrm{Ne}^{\mathrm{O}+}, \mathrm{Ar}^{10+}$ & DC-operation \\
\hline \multirow[t]{2}{*}{ Ithaca/Corncll } & Kostroun & CEBIS-I & warm & $A r^{16+}, X e^{28+}$ & atomic physics \\
\hline & & CEBIS-II & LHe & $\mathrm{Ar}^{10+}$ & atomic physics \\
\hline \multirow[t]{2}{*}{ Livermore/LLNL } & Marrs/Levine & EBIT-I & LHe & & under upgrade \\
\hline & & EBIT-II & $\mathrm{LHe}$ & $\mathrm{Ar}^{18+}, \mathrm{Xe}^{28+}, \mathrm{Th}^{80+}$ & atomic physics \\
\hline Manhattan/KSU & Stockli/Cocke & KSU-CRYEBIS & $\mathrm{LHe}$ & $\mathrm{Ar}^{18+}, \mathrm{Kr}^{3+}, \mathrm{Xe}^{\mathrm{Ht}+}$ & 7 atomic beam lines \\
\hline
\end{tabular}


techniques and equipment. For cxample, recently the effect of gas mixing to beost the yiclds through inn-ion cooling wits investigated [33] The group is also working on he development of simplified and/or minialurized EBISes using permanent magnets or no magnets at ali which nalurally produce lower charge states because of the reduced clectron beam densities [32].

\section{The Japanesc Electron Bcam Ion Sources}

In 1977 the Institute of Plasma Physics at Nagoya University started to invite Japanese physicists to Nagnoya to study atomic processes involving highly charged ions, consiclered to be very important in high tcmperature plasmas. The initial Proto-NICE EBIS (Naked Ion Collision Experiments) was followed by a cryogenic version NIC:E-1. which became operational in 1980. The source was operated in a DC-node, which reduced the energy spread to less than $1 \mathrm{eV}$ per charge [3.1]. The ion production included fully stripped ions up to neon, and very highly charged ions such as $\mathrm{Kr}^{25+}$ and $\mathrm{I}^{22}$. The few thousand ions per second oblained for the highest charge states were suflicient to measure the processes of interest, mainly electron capture in collisions with neutral atoms, which was studied in great detail, and included energy gain spectroscopy, taking advantage of the low energy spread. The results of this rescarch were reported in 18 refereed publications over a 4 year period [35]. Although NICE-1 is still operational, there is limited aclivily since the NIC.E group was dissolved in 1984

Okuno, a member of the former NICE group, constructed at the Tokyo Metropolitan University a MINI-EBIS with a normal-conducting solenoid, cooled with liquid nitrogen. This compact, low-cost EBIS produces up to bare oxygen, up to $\mathrm{Ne}^{\circ *}$ and $\mathrm{Ar}^{10}$ ions, which is excellent, considering the DC-operation and the limited electron beam density obtained with the $1 \mathrm{k}$ (7) field [36].

\section{Electron Beam Ion Sources in the U.S.}

The first EBIS built at Cornell University, CEBIS-I, is the best "warm" EBIS ever buili and accordingly is still in operation. Room temperature EBISes were typically limited by the low electron beam compression obtained with classical solenoids and the ion recombination in the high residual gas pressures. However, an

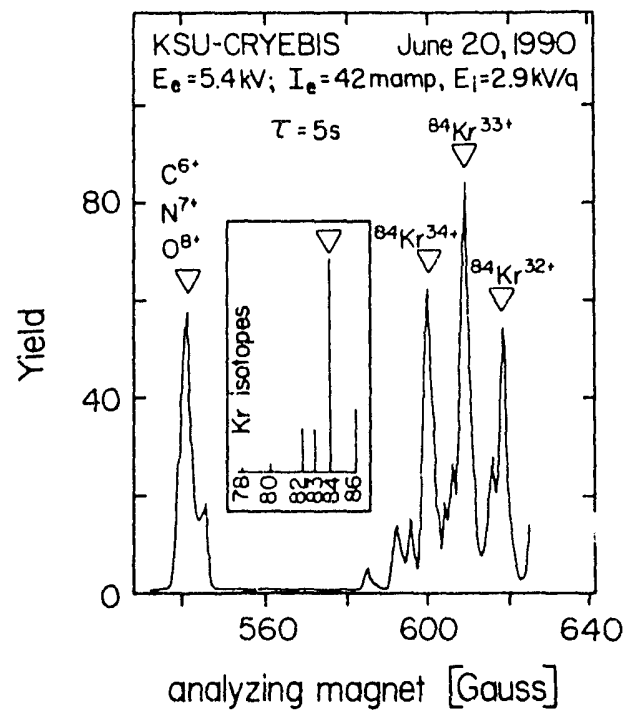

Fig. 2. Relative ion yields of highly chariged krypton obtained with an electron beam energy below the K-ionization threshold. The insert shows the scaled isotope pattern. The triangles point to the dominant iosotope 84 and shows $\mathrm{Kr}^{33+}$ to be the most abundant charge state. integrated ion pump creates a very low internal pressure inside CEBIS-I, which permits very long confinement imes and hence the production of ions like $A r^{16}$ and $x e^{2 *}$. A detisiled study of the trapped ions regarding heating and cooling was published $[37\}$ and studies of clectron capture by extracted ions colliding with beams are underway. CEBIS-II is Corncll's cryogenic EBIS, which was recently upgraded and redesigned to fit into an economical, off-the-shelf 3 Tesla solenoid [38]. So far it has been operated with an electron beam energy up $10.3 .5 \mathrm{kV}$, sufficient to produce the desired $\wedge r^{\text {th. }}$. Desplite the pulsed operation, a beam with an energy spread as little as $2 \mathrm{eV}$ per charge was produced, very important for the energy gain and loss studies in progress [39]. A study of electron emission induced by the highly charged ions incident on a surlace is also underway.

EBIT-1 and EBIT-II, the Eleciron Beam Ion Traps at Livermore National Laboratory in Livermore, were designed 10 produce and study the highly charged ions in sim. A pair of Helmholl: coils (in licu of the traditional long solenoid) generates the rather short 3 Tesla solenoidal lield. The shortness reduces complexity and problems which can be encountered with the electron beam transmission $[*(0)$. Indeed the traps became operational after a very short time required for design, construction, installation and startup. The wo traps, which were essentially identical, reach high current densities, high electron energies and have a very low background pressure, and therefore produce record charge states. Beryllium windows in the center between the two Helmholtz coils permil the observation of $X$-rays emilted in a radial direction. The emitted $X$-rays were used to demonstrate that the highly charged ions can be stored for hours, if proper cooling is applied [41). The results on ion cooling are in good atgreement with computer model calculations [42]. These novel tools for research on energetic electrons interacling with highly charged ions produced a large amount of novel data, such as clectron impact excitation and radiative recombination $[4.3,4-1]$, dicleatronic recombination $[45,+6], x-$ ray excitation $[+7)$ and polarization $[4 S]$, and precision wavelenglh measurements [fi]. However, the strong magnetic field limits the research to processes which lead to $X$-rily

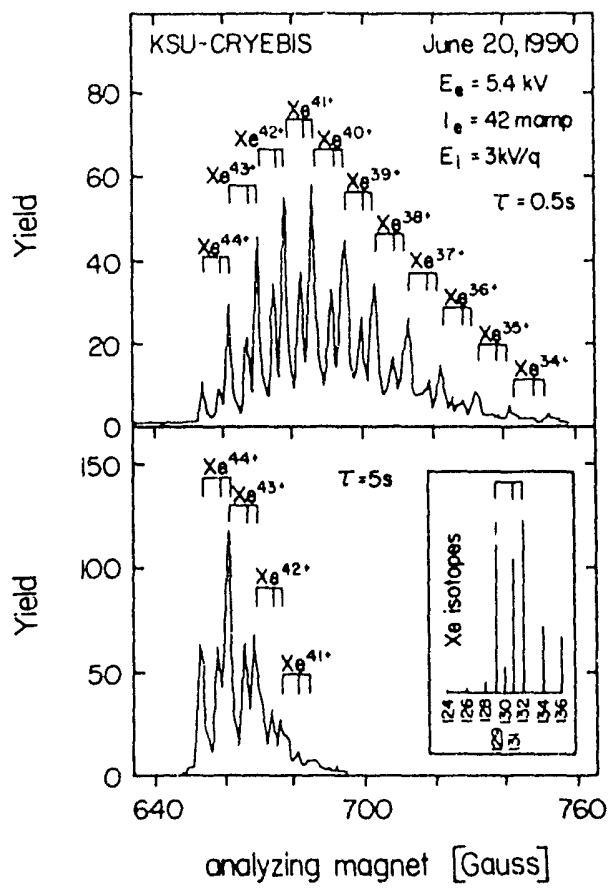

Fig. 3. Relative ion yields of highly charged xcnon obtained with an electron beam encrgy below the L-ionization threshold. The insert shows the scaled isotope pattern. The fork symbols point to the three dominant isotopes. The figure demonstrates how the intensity of the highest charge states grow, when the confinement time is increased from 0.5 seconds (top) to 5 seconds (bottom). 
emission. This limitation was recently overcome when the group started to extract the ions through a hole in the collector and analyzed ion beams of up to $\mathrm{Ar}^{18 *}, \mathrm{Xe}^{18^{*}}, \mathrm{U}^{71 *}$, and $\mathrm{Th}^{80 *}$, the record charge state for low energy ions [50]. Naturally the short trap length limits the ion yicld, although it is more than adequate for most experiments, such as the studies of recombination on surfaces underway [50]. Presently EBIT-1 is upgraded in a quest for higher charge states obtained with higher electron beam energies.

\section{The Latcist Addition: The KSU-CRYEBIS Facility}

The KSU-CRYEBIS was designed as a standard cryogenic EBIS similar to CF. YEBIS-II and DIONE and incorporated some ideas from EBIT [51,52]. After several years of construction and installation, it started to operate on Easter Salurday 1989. Within a few months tho production of bare argon was confirmed and shown to be the most ahundant argon charge stilte for a contianment time of two seconds [53]. More recently $\mathrm{Kr}^{34}$ and $\mathrm{Xe}^{+4}$ were produced as shown in Figures 2 and 3 . All these results were obtained with an electron beam energy of approximately $5.5 \mathrm{kV}$, the present hardware limit, which will be upgraded in the future. However, novel physics is not restricted to the highest charge states. For example, it was shown that the EBIS is a perfect device for an accurate measurement of the dielectronic recombination probabilities in comparison to the ionization probabilities, because no solid angle or beam overlap has to be estimated [54]. The case of the dielectronic recombination of the helium-like ions versus the ionization of the lithium-like ions is amazingly simple to analyze, because it involves only two charge states, as long as the electron beam energy is below the K-ionization threshold. The equilibrium yield of the helium-like ions is determined by the ionization rate of the lithium-like ions and the loss rate of helium-like ions through radiative recombination and through capture from the residual gas. But, whenever the electron beam energy is in resonance with a double excited state of the lithium-like ion, the dielectronic recombination will dramatically increase the loss rate of the helium-like ions, as shown in Figure 4 [from ref. 55]. Thuse measurements have becn completed for argon [55] and neon by probing the equilibrium ion yields. Naturally this method does not reveal processes without a net change of charge, such as dielectronic recombination followed by autoionization of the double excited state. Therefore, these studies were complemented by observing the $X$-rays emitted in an axial direction through the collector and through a

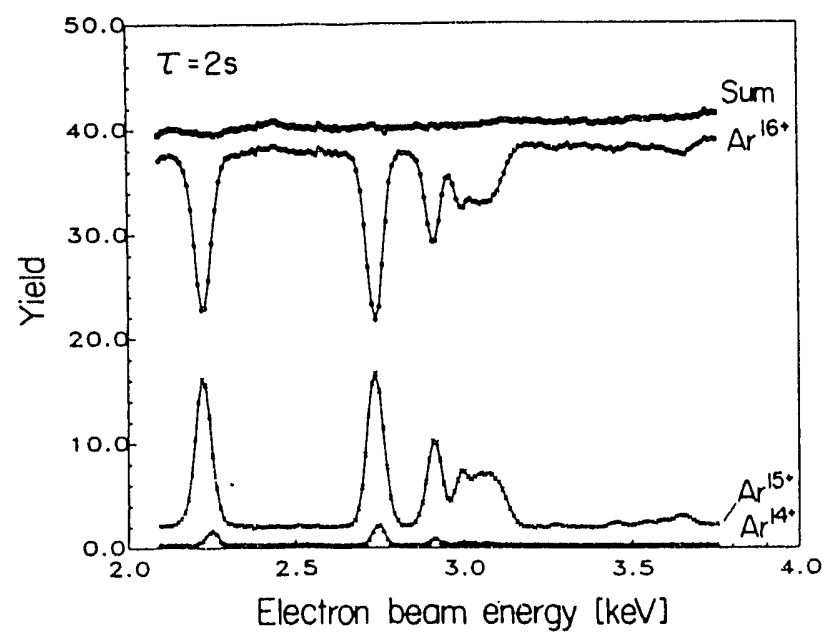

Fig. 4. Equilibrium ion yiclds (after confinement of 2 seconds) for $\mathrm{Ar}^{\mathrm{it}}, \mathrm{Ar}^{15 *}$, and $\mathrm{Ar}^{10}$ as a function of the electron beam energy. Whenever the electron beam energy is in resonance with a doubly excited state of $\mathrm{Ar}^{15 *}$, the $\mathrm{Ar}^{15+}$ yield will increase through dielectronic recombination of the $\mathrm{Ar}^{10 .}$. The top line shows the sum of the three charge states [from ref. 48 ]. window in the 0 degree $p$. of the analyzing magnet $[55,56]$. The small solid angle of the X-ray detector is partly compensated through the apparently high source dersity when observing on axis. This is another example in which an EBIS is used to study atomic physics in situ, although it was designed as an ion source. As an ion source it delivered beams of highly charged ions impacting on a surface to study the recombination processes, which strongly depend on the ion velocity [57].

The KSU-CRYEBIS was designed as a facility for atomic physics with highly charged, low energy ions. Therefore it is located on a high vollage plattorm which allows one to accelerate the tons up to $200 \mathrm{kV} /$ charge. The extraction beam line with the neecessary diagnostic devices and ion optical elernents transports the beam to the switching magnet [58] which injects the beam into one of the seven beam lines. This setup, shown in Figure 5, allows for a very efficient switching between different experiments and will dramatically broaden the number of problems which can be studied in the same time perind. Being a national user facility we strongly encourage the atomic physics community to make use of this novel atomic probe in our facility.

\section{Conclusions}

As discussed, the presently operational Electron Beam Ion Sources produce very highly charged ions. The produced ion beams and in sitt experiments continue to contribute substantially to physics research, especially to the atomic physics of highly charged ions. The artivity is expected to increase, as new projects will come on line. Two EBIT-like sources are under construction in Oxford, England, one for

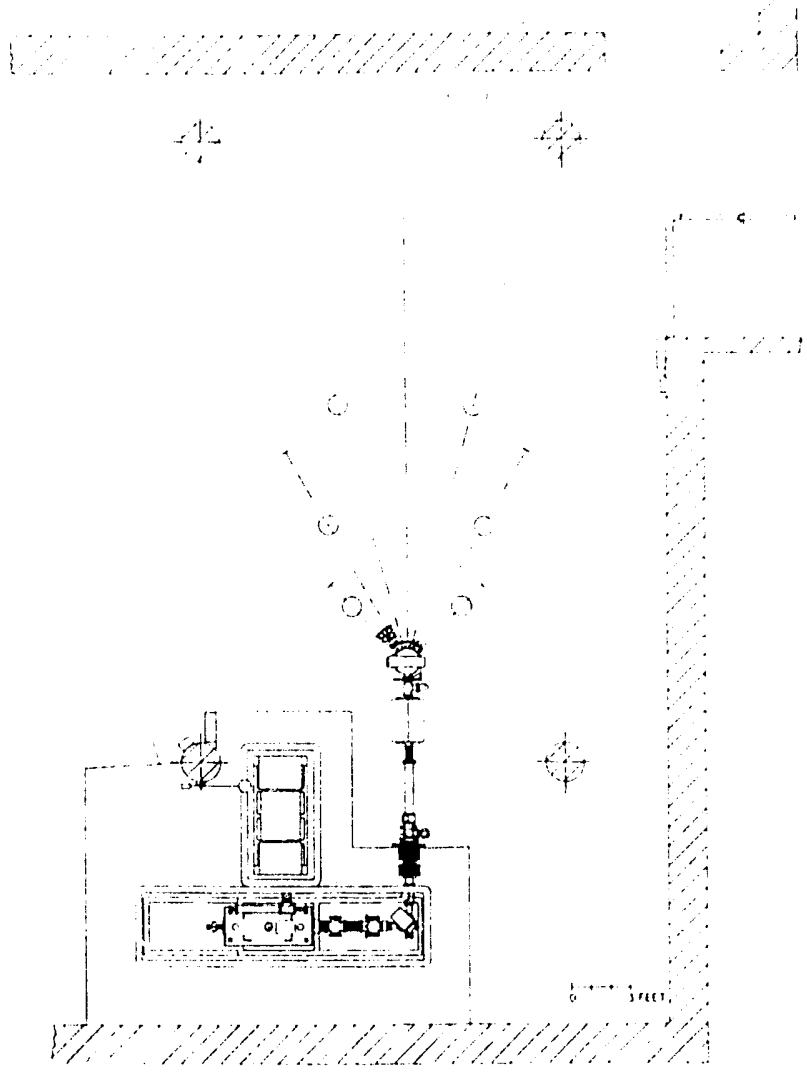

Fig. 5. Setup of the KSU-CRYEBIS facility. The CRYEBIS is located on a $200 \mathrm{kV}$ T-shaped platform inside a protective cage. After being analyzed in a 90 degree magnet, the ions enter the extraction beam line through the accelerator columns. The switching magnet directs the beam into one of the seven indicated atomic beam lines. The circles show the tentative target locations. The shaded areas represent the building walls and support columns. 
local use and the other for the U.S. National Institute of Standards and Technologies. A similar project is under development [59]. The new projects underline the fact that Electron Beam Ion Sources have become reliable tools to study the physics of highly charged ions.

\section{Acknowledgments}

I am grateful to A. Bárány, R. Becker, C.L. Cocke, E.D. Doncts, M. Kleinod, V. Kostroun, R. Marrs, D. Richard, and D. Schneider who contributed to this paper through discussions, suggestions, and proof reading. This work is supported by the Division of Chemical Sciences, Office of Basic Energy Sciences, Office of Energy Research, U.S. Department of Energy.

Refcrences

1. Donets E.D.: USSR Inventor's Certificate No. 248560), March 16, 1967, Byull. OIPOTZ No. 23, 65 (1969).

2. Levine M.A., Marrs, R.E., Henderson J.R., Knapp D.A., Schncider M.B., Physica Scripla T22, 157 (1988).

3. Levine M.A., Schneider M.B.: in "Proceedings of the International Conference on ECR Ion Sources, East Lansing, 1987", National Superconducting Cyclotron Laboratory, Michigan State University Report MSUCP-47, 233 (1988).

4. Donets E.D., Shirkov C.D., Avtorskoc Svidetelstvo USSR, N1225420 (02.07.1984), Bul. Ol, N44, 69 (1989).

5. Hershcovitch A., editor: "International Symposium on Electron Beam Ion Sources and Their Applications, Upton, NY, 1988", AIP Conf. Proc. No. 188, (American Institute of Physics, New York, 1989).

6. Donets E.D.: in "The Physics and Technology of lon Sources" Brown I.Ci. edt., (John Wiley \& Sons, Ncw York) 245 (1989).

7. Schmieder R.W.: in "Physics of Highly-lonized Aloms" Marrus R. ed., (Plenum Publishing Corp.) 321 (1989).

8. Arianer J., Cabrespine A., Goldstein C.: Nucl. Instrum. and Meth. 193,401 (1.982).

9. Donets E.D., Monchinsky V.A.: "Quatricmes Journees D'edudes Saturne La Physique avec Mimas, LaLonde-les Maures, 1986" (Laboratoire National Saturne, 91.191 Gif-sur-Yvette Cedex, France), 310 (1987).

10. Ovsyannikov V.P.: Vth Int. Conf. on the Physics of Highly-Charged Ions, Giessen, Germany, 1990, Book of Abstracts, 5.13 (199()).

11. Donets E.D.: Nucl. Instrum. Mcthods B9, 522 (1985).

12. Donets E.D.: "Int. Conf. on Ion Sources, Berkeley, CA, (1989).

13. Donets E.D., Ovsyannikov V.P.: JINR Commun. P7-10438, Dubna, (1977).

14. Donets E.D., Kartashov S.V., Ovsyannikov V.P.: JINR Rapid Commun. 20.86, 27 (1986).

15. Donets E.D.: Rev. Sci. instrum. 61, 225 (19\%).

16. Donets E.D., Ovsyannikov V.P.: Sov. Phys. JETP 53,466 (1981).

17. Donets E.D.: Physica Scripta $\underline{T 3}, 11$ (1983).

18. Donets E.D., Trifonov V.A., Tutin G.A., Eismont V.P.: JINR Commun. P7-83-573, Dubna, (1983).

19. Doncts E.D., Dudnikov, V.G., Dunin V.B., Karlashov S.V.: this conference (1991).

20. Olivier M., Faure J., Laclare J.L., Lefebvre J.M., Leleux G., Ropert A., Tkatchenko A., Tkatehenko M., IEEE Trans. Nucl. Sci. NS-30, 1463 (1983).

21. Faure J., Antoine P., Ciret J.C., Degueurce L., Gros P., Courtois A., Gastineau B., Gobin R., Leaux P., Leroy P.A., Penicaud J.P. in reference [5], 102 (1989).

22. C.ERN Courier, September 1989, p. 17.

23. CERN Couricr, November 1989, p. 37.

24. Briand J.P., Charles P., de Billy L., Essabaa S., Mchami A., Bliman S.: Bull. APS $\underline{35}, 1167$ (1990).

25. Briand J.P.: private communication (1990).

26. Herrlander C.J.: in ref [5], 379 (1989).
27. Liljeby L., Engstrom A.: in ref [5], 27 (1989).

28. Andersson H., Astner G., Cederquist H.: J. Phys B21, L1S7 (198S).

29. Cederquist H., Andersson H., Astner G., Heclplund P., Pederson J.O.P.: Phys. Rev. Lett. 62, 1 165.5 (1989).

30. Anderson H., Cederquist H., Astner G., Helplund P., Pedersen J.O.P., Physica Scripta 42, 150 (1990).

31. Cederquist H.: this conference (1991).

32. Kleinod M., Becker R., Klein H.: in ref [5], 15 (1989).

33. Becker R., Kleinod M.: this conference (1991).

34. S. Ohtani, Physics Scripta T3, 110 (1983).

35. "The collected Papers of NICE Project / IPP, Nagoya" Tawara H.: edt., IPP-AM-43, (Institutc of Plasma Physics, Nagoya University. 1985).

36. Okuno K.: in ref. [5], 33 (1989).

37. Becbe E.N.: in ref. $[5], 166(1989)$.

38. Kostroun V.O.: in ref. [5], 65 (1989)

39. Kostroun V.O., privatc communication (1990).

40. Levine M.A., Marrs R.E., Bennell C' L., Henderson J.R., Knapp D.A., Schneider M.B.: in ref. [5], $\$ 2$ (1989).

41. Schneider M.B., Levine M.A., Bennell C.L., Henderson J.R., Knapp D.A., Marrs R.E., in ref. [5], 158 (1989).

42. Penctrante B.M., Levine M.A., Bardsley J.N., in ref. [5], 14.5 (1989).

43. Marrs R.E., Levine M.A., Knapp D.A., Henderson J.R.: Phys Rew. Lell. 60,715 (1988).

44. Marrs R.E., Levine M.A., Knapp D.A., Henderson J.R.: in "Electronic and Atomic Collisions" Gilbody H.B., Newell W.R. Read F.H., Smith A.C.H. eds., (Elsevicr Science Publisher) 209 (1988).

45. Knapp D.A., Marrs R.E., Levine M.A., Bennett C.L., Chen M.H., Henderson J.R., Schneider M.B., Scofield J.H.: Phys. Rev. Lell. Q2 2104 (1989).

46. Beiersdorfer P. al al:: Phys. Rev. Lett. (1990).

47. Marrs R.E., Beiersdorfer P., Bennell C., Chen M.H., Cowan T., Dietrich D., Henderson J.R., Knapp D.A., Osterheld A., Schneider M.A., Scofield J.H.: in ref. [5], 445 (1989).

48. Henderson J.R., Beicrsdorfer P., Benncle C.L., Chantrenne S. Knapp D.A., Marrs R.E., Schncider M.B., W'ong K.L., Duscheh (i.A., Secly J.F., Brown C.M., LaVilla R.E., Dubau J., Levine M.A.: Phys. Rev. Lelt. 65, 705 (19:00).

49. Levine M.A., Marrs R.E., Bardsley J.N., Beiersdorfer P., Benneu C.L., Chen M.H., Cowan T., Dietrich D., Henderson J.R., Knapr D.A., Osterheld A., Penetrante B.M., Schneider M.A., Scofield J.H.: Nucl. Instrum. and Meth. B+3, 431 (1989).

50. Schneider D., DeWill D., Clark M.W., Schuch R., Cocke C.L. Schmieder R., Reed K.J., Chen M.H., Marrs R.E., Levine M., Fortner R.: Phys. Rev. A 42, 3459 (190)).

51. Stockii M.P., Arianer J., Cocke C.L., Richard P., Nucl. Instrum. and Meth. B B $40 / 411020$ (1.989).

52. Stockli M.P., Cocke C.L., Richard P.: in ref. [5] 114 (1989).

53. Stockli M.P., Cocke C.L., Richard P.: Rev. Sci. Instrum. 61, 242 (1990).

54. Ali R., Bhalla C.P, Cocke C.L., Stockli M.P.: Phys. Rev. Lett. $\underline{6}$, 633, (1990).

55. Ali R., Bhalla C.P, Cocke C.L., Schulz M., Stockli M.P.: submitted to Phys. Rev. A (1990).

56. Ali R., Bhalla C.P, Cocke C.L., Schulz M., Stockli M.P.: this conference (1991).

57. Schulz M., Cocke C.L., Stockli M.P., Hagmann S.: this conference $(1901)$

58. Courtesy of Western Michigan University.

59. e.g. Antsiferov P.S., Movshev V.G.: this conference (1991). 

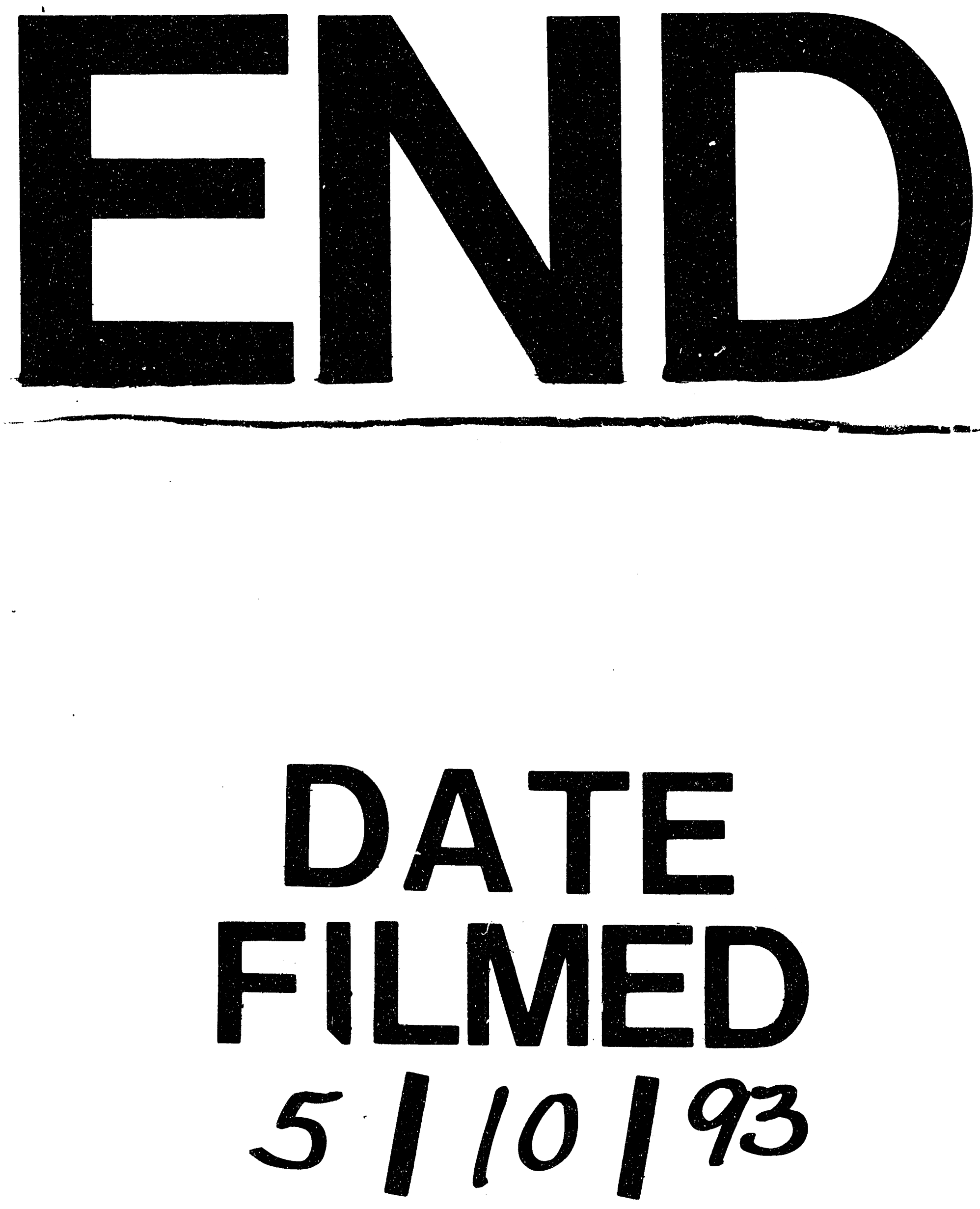
